\title{
ATITUDES EMPREENDEDORAS DOS PARTICIPANTES DO PROGRAMA ESTADUAL "BOM NEGÓCIO PARANÁ", NO MUNICÍPIO DE FRANCISCO BELTRÃO/PR
}

\author{
Data de submissão:10/03/2014 \\ Aceite: $21 / 05 / 2016$ \\ Elisane Bach ${ }^{1}$ \\ Gilberto Francisco Ceretta ${ }^{2}$ \\ Adilson Carlos Rocha ${ }^{3}$
}

\section{RESUMO}

O presente estudo tem por objetivo analisar a existência de diferenças nas atitudes dos empreendedores em relação aos setores econômicos nos quais estão inseridos os empreendimentos dos participantes do programa estadual "Bom Negócio Paraná", do município de Francisco Beltrão/PR. O estudo foi realizado entre os meses de março e agosto de 2013. Para a coleta de dados, foi utilizado um modelo desenvolvido por Lopez Jr. (2005) denominado Instrumento de Medida de Atitude Empreendedora - Imae. O questionário aplicado utilizou-se de uma escala de mensuração do tipo Likert de 10 pontos com uma amostragem de 101 respondentes. 0 estudo desenvolveu-se por meio de uma abordagem quantitativa, na qual os dados receberam tratamento pela estatística descritiva. Em uma análise comparativa das dimensões, a realização apresentou maiores médias gerais de concordância, seguida pela inovação, poder e, por fim, planejamento. Comparando os setores indústria, comércio e serviços, verificaram-se diferenças tênues entre eles. Desse modo, a pesquisa propôs uma perspectiva diferente de análise em relação ao trabalho de Bosma e Schutjens (2007), que exploram as atitudes empreendedoras com diferenciações espaciais na Europa, analisando o atributo de setores econômicos como vetores de distinção.

Palavras-chave: Empreendedorismo; Atitude empreendedora; Programa Bom Negócio.

\footnotetext{
1 Possui graduação em Administração pela Universidade Estadual do Oeste do Paraná. Francisco Beltrão, PR - Brasil. E-mail: elisanebach@hotmail.com 2 Possui graduação em Administração de Empresas pela Universidade Estadual de Ponta Grossa - UEPG, mestrado em Administração pela Universidade Federal do Paraná - UFPR e Doutorado no Programa de Mestrado e Doutorado em Administração - PMDA da Universidade Positivo - UP. Professor adjunto da Universidade Estadual do Oeste do Paraná - Unioeste, Campus de Francisco Beltrão. Francisco Beltrao, PR - Brasil. E-mail: gilbertoceretta@gmail.com 3 Possui graduação em Administração pela Universidade Tecnológica Federal do Paraná, UTFPR, mestrado em Administração pela Universidade Federal de Santa Maria, UFS e doutorado em Administração pela Universidade Positivo, POSITIVO. Francisco Beltrão, PR-Brasil. E-mail: adilson28@hotmail.com
} 


\section{INTRODUÇÃO}

O empreendedorismo vem conquistando destaque em muitos setores, seja em instituições educacionais ou unidades governamentais, seja na sociedade em geral. Seu ensino na academia se consolidou, passando a ser uma disciplina em diversos cursos de graduação; como consequência disso, a produção científica vem ganhando força e proporcionando maior contribuição para o tema e a construção de novos conhecimentos.

No Brasil, cria-se anualmente mais de 1,2 milhão de novos empreendimentos formais. Desse total, mais de $99 \%$ são micro e pequenas empresas e empreendedores individuais, os quais são responsáveis por mais da metade dos empregos formais no país. Somando-se a isso a ocupação que os empreendedores geram para si mesmos, pode-se pensar que os empreendimentos de micro e pequeno porte são responsáveis por, pelo menos, dois terços do total das ocupações existentes no setor privado da economia (SEBRAE, 2012).

Diante desse breve contexto sobre a importância do empreendedorismo para a realidade econômica nacional, a academia esforça-se em abordar e gerar conhecimentos específicos para a atividade empreendedora. Greatti e Senhorini (2000) afirmam que, entre as pesquisas na área de empreendedorismo, encontram-se aquelas que analisam a personalidade, habilidades e atitudes, numa tentativa de explicar as características próprias dos empreendedores. Entre os assuntos estudados, está a atitude dos empreendedores que tenta traçar um perfil comum entre indivíduos que exercem algum tipo de empreendedorismo. Segundo Bosma e Schutjens (2007), as pessoas possuem valores individuais e preferências e avaliam distintamente suas próprias capacidades, além de perceberem as oportunidades e tomarem decisões de forma particular. No empreendedorismo, as atividades muitas vezes estão condicionadas a características de personalidade e também de atitudes socioculturais e impedimentos regulamentares, isso possibilita uma diferenciação espacial nas atitudes de empreendedores.

Mesmo com uma gama de estudos que relacionam as atitudes empreendedoras e suas possíveis variações regionais, há muitas lacunas a serem dirimidas, entre elas, a existência de variação de atitudes conforme o setor econômico de atuação. Desse modo, o objetivo da pesquisa é analisar a existência de diferenças nas atitudes dos empreendedores em relação aos setores econômicos nos quais estão inseridos os seus empreendimentos, baseando-se em uma população específica, participante de um programa estadual de apoio a micro e pequenos empreendedores, denominado "Bom Negócio Paraná", localizados no núcleo de Francisco Beltrão, no estado do Paraná.

Para o alcance do objetivo proposto, o artigo está estruturado, além desta introdução, da seguinte forma: o referencial teórico, em que são apresentadas conceituações pertinentes ao entendimento do assunto; o método utilizado, no qual se discutem o instrumento de pesquisa usado para a obtenção dos dados, bem como as técnicas de análise dos dados; o cenário onde se desenvolveu a pesquisa; a análise dos resultados, na qual são apresentadas as características da amostra determinada, bem como os resultados das dimensões utilizadas na investigação das atitudes empreendedoras explicitadas pelo modelo proposto e, como forma de atingir o objetivo do estudo, o teste de correlação utilizado; e, por fim, as considerações finais.

\section{REFERENCIAL TEÓRICO}

\subsection{Empreendedorismo}

O primeiro uso do termo "empreendedorismo" foi registrado por Richard Cantillon, em 1755, para explicar a receptividade do risco de comprar algo por um determinado preço e vendê 
-lo em um regime de incerteza. Jean Baptiste Say, em 1803, ampliou essa definição, passando a relacionar empreendedorismo à transferência de recursos econômicos de um setor de produtividade mais baixa para um setor de produtividade mais elevada e com maior rendimento, ficando convencionado que quem abre seu próprio negócio é um empreendedor (HASHIMOTO, 2010).

Para Dornelas (2001, p. 37), a definição que melhor define o espírito empreendedor é a de Joseph Schumpeter (1949), segundo o qual "o empreendedor é aquele que destrói a ordem econômica existente pela introdução de novos produtos e serviços, pela criação de novas formas de organização ou pela exploração de novos recursos e materiais".

De acordo com Bittar, Bastos e Moreira (2014), as primeiras definições sobre empreendedor seguiam uma lógica evolutiva, inseridas no contexto histórico e nas experiências específicas de cada pesquisador. Para melhor entendimento da evolução histórica do termo e sua contribuição para a sociedade ao longo do tempo, no Quadro 1, apresenta-se uma síntese das diferenças existentes na concepção e na construção do termo "empreendedor", desde sua origem até o século XX.

Quadro 1 - Histórico do termo "empreendedor"

\begin{tabular}{|c|l|}
\hline \multicolumn{2}{|c|}{ Histórico do termo "empreendedor" } \\
\hline Origem & $\begin{array}{l}\text { O termo "empreendedor" (entrepreneur) tem origem francesa e quer dizer "aque- } \\
\text { le que assume riscos e começa algo novo". }\end{array}$ \\
\hline $\begin{array}{c}\text { Primeiro uso do ter- } \\
\text { mo "empreendedo- } \\
\text { rismo" }\end{array}$ & $\begin{array}{l}\text { Um primeiro exemplo de definição pode ser creditado a Marco Polo, que tentou } \\
\text { estabelecer uma rota comercial para o Oriente. Ele assinou um contrato com um } \\
\text { homem que possuía dinheiro para vender as mercadorias daquele. Enquanto o } \\
\text { capitalista era alguém que assumia riscos de forma passiva, o aventureiro empre- } \\
\text { endedor assumia papel ativo, correndo todos os riscos físicos e emocionais. }\end{array}$ \\
\hline Idade Média & $\begin{array}{l}\text { O termo "empreendedor" foi utilizado para definir aquele que gerenciava grandes } \\
\text { projetos de produção. O indivíduo não assumia grandes riscos, apenas gerenciava } \\
\text { os projetos, utilizando os recursos disponíveis. }\end{array}$ \\
\hline Século XVII & $\begin{array}{l}\text { O empreendedor estabelecia acordo contratual com o governo para realizar algum } \\
\text { serviço ou fornecer produtos, os preços eram prefixados e qualquer lucro ou pre- } \\
\text { juízo era exclusivo do empreendedor. }\end{array}$ \\
\hline Século XVIII & $\begin{array}{l}\text { O capitalista e o empreendedor foram finalmente diferenciados, provavelmente } \\
\text { devido ao início da industrialização que ocorria no mundo. }\end{array}$ \\
\hline Séculos XIX e XX & $\begin{array}{l}\text { Os empreendedores foram frequentemente confundidos com os gerentes ou ad- } \\
\text { ministradores, sendo analisados meramente de um ponto de vista econômico, } \\
\text { como aqueles que organizam a empresa, pagam os empregados, planejam, diri- } \\
\text { gem e controlam as ações na empresa, mas sempre a serviço do capitalista. }\end{array}$ \\
\hline
\end{tabular}

Fonte: adaptado de Dornelas (2001).

Segundo Hisrich, Peters e Dean (2009), na maioria das definições de empreendedorismo, há um consenso sobre a abrangência do comportamento empreendedor: "tomar iniciativa, organizar e reorganizar mecanismos sociais e econômicos a fim de transformar recursos e situações para proveito prático e aceitar o risco ou o fracasso". Os mesmos autores reforçam que "empreendedorismo é o processo de criar algo novo com valor, dedicando o tempo e o esforço necessários, assumindo riscos financeiros, psíquicos e sociais e recebendo as consequentes recompensas da satisfação e da independência financeira e pessoal".

No Brasil, o termo "empreendedorismo" começou a tomar forma na década de 1990, quando entidades como o Serviço Brasileiro de Apoio às Micro e Pequenas Empresas (Sebrae) e a Sociedade Brasileira para Exportação de Software (Softex) foram criadas. Antes disso, praticamente não se falava em empreendedorismo e em criação de pequenas empresas e termos como planos de negócios eram desconhecidos. 


\subsection{0 empreendedor}

O empreendedor é aquele sujeito que tem um espírito livre e aventureiro, sendo capaz de gerar inovações tecnológicas, criar novos mercados, superar a concorrência e ser bem-sucedido nos negócios, assumindo os riscos do empreendimento; é o agente transformador da economia, o motor do crescimento. 0 empreendedor não se move pelo lucro, suas verdadeiras motivações estão no sonho, no desejo de conquistar, na alegria de criar, no entusiasmo para provar que é superior aos outros (SCHUMPETER, 1982).

Bessant e Tidd (2009) contribuem argumentando que as pessoas podem desenvolver um modo de vida empreendedor, quando procuram independência e desejam ganhar a vida com base nas suas possibilidades e valores pessoais; podem também ser empreendedores do crescimento, que são aqueles que têm como objetivo se tornar ricos e poderosos por meio da criação e do crescimento agressivo de novos negócios; e, por fim, são os indivíduos guiados pelo desejo de criar ou mudar algo, seja no setor privado, público ou de serviços, e a principal inovação é para mudar ou criar algo novo.

Conforme Bernardi (2003, p. 64), a definição predominante da figura do empreendedor conduz a um perfil característico e típico de sua personalidade, em que se destacam: "senso de oportunidade, dominância, autoconfiança, otimismo, independência, persistência, criatividade, propensão ao risco, liderança carismática e habilidade de relacionamento". Em artigo cujo objetivo era caracterizar o comportamento empreendedor de presidentes de associações apícolas do Rio Grande do Sul, Lengler (2008) concluiu que, mesmo com inúmeras e distintas definições sobre o perfil do empreendedor, há uma convergência entre as noções de criatividade, inovação, criação, dedicação e disposição para assumir riscos e aproveitar oportunidades.

\subsection{Atitude empreendedora}

Segundo Ajzen (2001), a atitude continua a ser um foco em teoria e pesquisa nas ciências sociais e comportamentais. Suas principais funções, amplamente reconhecidas por pesquisadores, são: (i) expressiva de valor; (ii) conhecimento; (iii) egodefensiva; (iv) social; e (v) utilitária. No campo do empreendedorismo, as atitudes dos empreendedores são características adquiridas ao longo de sua vida, que influenciam o seu comportamento diante de uma situação, determinando a forma como conduzem os negócios e servem de orientação para o seu trabalho.

Beugelsdijk e Noorderhaven (2004) afirmam que a medição da atitude empreendedora é difícil, no que tange à obtenção de dados, o que explica em parte a escassez de estudos empíricos sobre o assunto. De acordo com Lopez Jr. (2005), na década de 1970, McClelland (1972) concentrou seus estudos na tentativa de identificar quais características do comportamento empreendedor são, frequentemente, apresentadas por indivíduos com elevado desempenho profissional e alto grau de realização. Em seus estudos, ele identificou algumas das principais características e as agrupou em três dimensões: realização, planejamento e poder.

Para constituir um modelo que busque avaliar a atitude empreendedora, foram consideradas as três dimensões - realização, planejamento e poder -, acrescidas de outra dimensão, constituída pelas variáveis inovação e criatividade, dimensão esta incluída no modelo proposto por Lopez Jr. (2005). Tais dimensões compuseram o Instrumento de Medida de Atitude Empreendedora (Imae), com a finalidade de mensurar a atitude empreendedora em proprietários-gerentes de pequenas empresas.

As dimensões realização, planejamento, poder e inovação serão as características da atitude empreendedora utilizadas para a realização deste estudo. Sendo assim, torna-se necessário pautar cada uma dessas dimensões para melhor entendimento da pesquisa desenvolvida. 


\subsubsection{Inovação}

A dimensão inovação subdivide-se em criatividade e inovação e encontra-se voltada para a capacidade do empreendedor de atuar de forma criativa e inovadora na busca por posições vantajosas de mercado (LOPEZ JR., 2005).

Em meados do século XX, estabeleceu-se a noção de empreendedor como inovador. A função do empreendedor é reformar ou revolucionar o padrão de produção, explorando uma invenção ou, de modo mais geral, um método tecnológico não experimentado, para produzir um novo bem ou um bem antigo de uma maneira nova, abrindo uma fonte de suprimento de materiais, ou uma nova comercialização para produtos, e organizando um novo setor. (HISRICH; PETERS; DEAN, 2009).

Schumpeter (1997) associa o empreendedor com a inovação, estando a essência do empreendedorismo na percepção e no aproveitamento das novas oportunidades no âmbito dos negócios. O empreendedor, segundo Schumpeter (1997), tem a função de realizar novas combinações nos canais de produção, tendo como resultado a constituição de um novo empreendimento; é a capacidade de implementação das novas possibilidades de combinação que destaca o empreendedor como uma categoria especial, que assegura o desenvolvimento econômico.

Conforme Drucker (2003), a inovação é o instrumento específico do espírito empreendedor, é o ato que contempla os recursos com a nova capacidade de criar riqueza. A inovação, de fato, cria um recurso, não existe algo chamado de "recurso" até que o homem encontre um uso para alguma coisa na natureza e assim o dote de valor econômico. Portanto, a inovação aumenta o rendimento dos recursos.

Bessant e Tidd (2009) enfatizam que a prática bem-sucedida da inovação e do empreendedorismo exige a interação e a integração de três diferentes perspectivas: pessoal, social e contextual, definidas como: (i) os atributos pessoais ou individuais que abarcam o estilo criativo e a habilidade de identificar, avaliar e desenvolver ideias e conceitos novos; (ii) os fatores sociais ou coletivos que compreendem a contribuição de equipes, grupos e processos indispensáveis à transformação de ideias e conceitos em novos produtos, serviços ou negócios; e (iii) os fatores contextuais que incluem o ambiente e os recursos necessários para tornar viável a criação e o crescimento da inovação e do empreendedorismo.

Mello, Machado e Jesus (2010), em seu ensaio teórico, cujo objetivo era discutir as diversas formas de inovação em micro e pequenas empresas, consideram essas instituições como geradoras de inovações, mesmo que de forma tímida, e concluem que deve haver um esforço nas condições de produção de novas ideias, sendo o conhecimento o fator essencial no processo de inovação.

\subsubsection{Realização}

O campo da realização compõe-se da busca de oportunidades e iniciativas, persistência, aceitação de riscos calculados, exigências de qualidade e eficiência e comprometimento. Conforme Marquesini (2007), a necessidade de realização é um conceito intrinsecamente relacionado à iniciativa e à persistência, que são dois indicadores para o conjunto de realização. A aceitação de riscos ou a tendência a assumir riscos moderados é outra característica que compõe o conjunto de realização, juntamente com a busca de novas oportunidades.

Segundo Lopez Jr. (2005), essa dimensão está relacionada à disposição do indivíduo na realização das tarefas, às novas formas encontradas de fazer as coisas - de modo mais rápido e com um menor custo -, à busca por novos produtos e à expansão dos negócios. Refere-se à preocupação, constante, com a alta qualidade e eficiência. Analisa os riscos envolvidos nos negócios, calculando os resultados esperados, buscando as melhores alternativas para alcançar os objetivos desejados. 
Segundo McClelland (1972), a dimensão de realização é formada por características comportamentais como busca de oportunidades e iniciativa (prospecção), persistência em enfrentar desafios e dificuldades não planejadas, aceitação de riscos com uma perspectiva calculada, senso de exigência de qualidade e eficiência em suas atividades e comprometimento completo com todo o seu empreendimento.

A necessidade de realização impele o indivíduo a buscar objetivos que envolvem atividades desafiantes, com uma acentuada preocupação em fazer bem e melhor, que não é determinada apenas pelas possíveis recompensas em prestígio e dinheiro. Pessoas movidas pela necessidade de realização canalizam muita energia para o aperfeiçoamento e progresso constantes em seus desempenhos e realizações, gostam de resolver problemas cuja resolução produza sentimento de competência pessoal (LOPEZ JR., 2005).

\subsubsection{Planejamento}

A dimensão planejamento, na visão de Lopez Jr. (2000), inclui as habilidades relacionadas ao planejamento e ao gerenciamento do negócio. São considerados como indicadores dessa dimensão "o estabelecimento de metas, a busca de informações e planejamento e o acompanhamento sistemático".

Robbins (2000) afirma que planejar envolve definir os objetivos ou metas da organização, estabelecer uma estratégia genérica para atingir essas metas e desenvolver uma completa hierarquia de planos para integrar e coordenar atividades. A preocupação é tanto com os fins (o que deve ser feito) quanto com os meios (como deve ser feito).

Já para Lopez Jr. (2005), através do planejamento, o empreendedor é capaz de dividir tarefas de grande porte em subtarefas com prazos definidos; revisar seus planos constantemente, levando em conta os resultados obtidos e mudanças circunstanciais; e manter registros financeiros, utilizando-os para tomar decisões.

Quando todos os envolvidos com o trabalho sabem para onde a organização está indo e como eles devem contribuir para atingir os objetivos esperados, podem coordenar suas atividades, cooperar uns com os outros e trabalhar em equipes. Sem o planejamento, os departamentos poderiam estar trabalhando com propósitos divergentes, impedindo a organização de se mover de forma eficaz na direção de seus objetivos.

\subsubsection{Poder}

A dimensão poder envolve a capacidade do empreendedor de influenciar os resultados em benefício próprio. Nesse item, busca-se definir poder e sua relação como a influência sobre os demais atores envolvidos no contexto do empreendedor (LOPEZ JR., 2005). Os indicadores considerados são: estabelecimento de redes de contato, persuasão, liderança, independência e autoconfiança.

Conforme Marquesini (2007), o poder é uma forma de influência na relação entre dois ou mais atores. Essa capacidade de influenciar outros atores com os quais se mantém relação é uma das características do comportamento empreendedor, influência essa que pode se manifestar por um processo de liderança, de motivação ou por um processo visionário, ou seja, o empreendedor utiliza sua capacidade de liderança para exercer com pessoas à sua volta uma influência positiva orientada para o desenvolvimento e a transformação.

Para Faria (1985), o poder pode ser definido como a capacidade que tem uma classe social ou um grupo social de definir e realizar seus interesses objetivos específicos, mesmo contra a resistência ao exercício dessa capacidade e independentemente do nível estrutural em que tal 
capacidade esteja principalmente fundamentada. O poder não é condição individual e tampouco um atributo coletivo; trata-se de uma capacidade coletiva, sendo que os indivíduos se inserem em suas relações a partir de vínculos e atividades que desempenham no âmbito coletivo, podendo influenciar, coordenar, liderar, organizar e mesmo conferir legitimidade.

Tipicamente, o poder é visto como a habilidade que determinado indivíduo tem de fazer com que os outros façam o que ele quer que seja feito, se necessário contra a própria vontade deles. Assim, o poder é concebido como a capacidade de agir do indivíduo e também como a capacidade de determinar o comportamento de outro indivíduo, é a ação do homem sobre o homem (CARVALHO; VIEIRA, 2007).

Ainda de acordo com Carvalho e Vieira (2007), nas organizações, isso se concretiza através de medidas hierárquicas internas, que, através de uma comunicação vertical, propõem níveis de autoridade, gerando relações de poder. Desse modo, acrescenta-se que a construção do discurso nas organizações está relacionada com quem detém o poder, visto que as chefias organizacionais manifestam suas decisões via práticas discursivas.

\section{MÉTODO}

O presente estudo se caracteriza como descritivo, com um corte transversal e abordagem quantitativa. Hair Jr. et al. (2005) afirmam que dados quantitativos são coletados a partir de números, tornando-se mais objetivos. Os resultados estatísticos não dependem da opinião do pesquisador e, por isso, eles fundamentam-se nas habilidades do pesquisador apenas como analista.

Para o desenvolvimento da pesquisa, foram considerados como população os inscritos nas cinco turmas do programa estadual "Bom Negócio Paraná", no município de Francisco Beltrão, no período de março a setembro do ano de 2013. A amostragem se deu pela operacionalização da coleta de dados, sendo representada pelos participantes do curso de capacitação presentes no primeiro dia do módulo de empreendedorismo e gestão em cada turma durante o prazo proposto para o levantamento dos dados, demonstrados na Tabela 1.

Tabela 1 - Inscritos e respondentes da pesquisa

\begin{tabular}{c|c|c|c}
\hline Turma & Inscritos & Respondentes & Total de participantes \\
\hline Março & 45 & 30 & $67 \%$ \\
\hline Junho & 30 & 19 & $63 \%$ \\
\hline Julho & 43 & 25 & $58 \%$ \\
\hline Agosto & 37 & 27 & $73 \%$ \\
\hline Total & 155 & 101 & $65 \%$ \\
\hline
\end{tabular}

Fonte: dados da pesquisa (2013).

Dessa forma, observou-se que 65\% dos inscritos no programa estadual "Bom Negócio Paraná" entre os meses de março e agosto de 2013 responderam ao questionário referente ao estudo sobre atitude empreendedora, totalizando 101 participantes.

A coleta de dados foi operacionalizada por meio de questionários aplicados aos participantes que estavam presentes no dia e horário propostos pela pesquisa. O questionário continha instruções de preenchimento, que reforçaram as explicações que foram repassadas pelos pesquisadores durante a realização do levantamento, caracterizando-se como uma aplicação direta.

O questionário utilizado para a coleta de dados foi composto de três blocos: 1ㅇ) perfil do respondente, em que foram coletadas informações como cargo da pessoa, idade, tempo de trabalho e formação acadêmica; $2^{\circ}$ ) caracterização da empresa, em que foram requisitados o tempo de atividade da empresa, setor de atuação, número de funcionários, receita operacional bruta e localização da empresa; 
3) aplicação do instrumento Imae, em que o participante respondeu a cada questão em uma escala de 1 a 10, sendo 1 para nunca e 10 para frequentemente em relação a suas atitudes empreendedoras.

Para a análise dos dados, primeiramente as respostas dos participantes ao questionário foram tratadas e registradas em um arquivo tipo planilha do Microsoft Office-Excel ${ }^{\circ}$ versão 2007. Após foi realizada uma análise descritiva dos dados que caracterizam o perfil do empreendimento e do participante respondente, com o uso de estatística descritiva. Em seguida, foram apuradas as medidas de tendência central, sendo elas a média e a moda para os itens de cada uma das dimensões do modelo Imae e utilizado o desvio-padrão como critério de homogeneidade entre as atitudes dos respondentes da pesquisa. De acordo com Dancey e Reidy (2006), as medidas de tendência central fornecem uma indicação do escore típico de um determinado conjunto, sendo a forma mais comum de estatística descritiva.

Após isso, foi executado um teste de normalidade para verificar qual tipo de testes estatísticos (paramétricos ou não paramétricos) poderia ser efetuado. Constatou-se que a distribuição não se apresenta com uma normalidade; sendo assim, tomou-se a decisão de utilizar o teste de Kruskal-Wallis, que "[...] compara várias condições quando diferentes pessoas participam em cada condição e os dados resultantes não são normalmente distribuídos ou não satisfazem as hipóteses paramétricas" (FIELD, 2009, p. 503).

$\mathrm{Na}$ identificação das diferenças significativas entre os grupos, foi utilizada a comparação múltipla das médias das ordens, o teste de Fisher (LSD - Lest-Significant- Difference), teste este conhecido como Post Hoc. De acordo com Maroco (2007), o método de Fisher compara todos os pares de médias, controlando a taxa de erro ao nível de significância $(\alpha)$, para cada comparação dois a dois, através do procedimento de testes múltiplos, cada um ao nível de significância $(\alpha)$. Para a realização dos testes estatísticos, foi utilizado o software estatístico SPSS ${ }^{\circ}$ (Statistical Package for the Social Science), versão 18.

\subsection{Imae - Instrumento de Medida da Atitude Empreendedora}

Denominado Instrumento de Medida de Atitude Empreendedora (Imae), o modelo utilizado para a realização do presente estudo foi desenvolvido por Lopez Jr. (2005) e tem como objetivo analisar a atitude empreendedora.

Para validar o instrumento, o autor aplicou o questionário com 290 respondentes, grupo constituído de proprietários-gerentes de pequenas empresas de comércio e serviços associados ao projeto "Empreender" no Distrito Federal. O projeto é resultado do trabalho conjunto da Confederação das Associações Comerciais do Brasil (CACB), da Federação das Associações Comerciais e Industriais do Distrito Federal e do Sebrae. O objetivo desse projeto foi a aproximação dos empresários de um mesmo setor, promovendo a interação na busca de soluções criativas para suas dificuldades, esquecendo a concorrência (LOPEZ JR., 2005).

O instrumento é constituído por 36 itens, os quais são divididos em quatro grandes dimensões ou conjuntos, que são: realização, planejamento, inovação e poder. O Quadro 2 sintetiza cada dimensão com seus principais indicadores e os itens utilizados pelo Imae.

Quadro 2 - Distribuição dos itens e indicadores segundo suas dimensões

\begin{tabular}{|c|c|c|}
\hline Dimensão & Indicadores & Itens \\
\hline Realização & $\begin{array}{l}\text { Busca de oportunidades/iniciativa, persistência, } \\
\text { aceitação de riscos e comprometimento. }\end{array}$ & $2,4,8,13,17,18,2027,30$ \\
\hline Planejamento & $\begin{array}{l}\text { Estabelecimento de metas, busca de informações e } \\
\text { planejamento, monitoramento. }\end{array}$ & $\begin{array}{c}3,5,6,9,12,15,16,19,22,29 \\
32,33,34\end{array}$ \\
\hline Poder & $\begin{array}{l}\text { Estabelecimento de redes de contatos, persuasão, } \\
\text { liderança, independência e autoconfiança. }\end{array}$ & $7,10,14,24,25,26,35,36$ \\
\hline Inovação & Criatividade e inovação. & $1,11,21,23,28,31$ \\
\hline
\end{tabular}

Fonte: adaptado de Lopez Jr. (2005). 


\section{CENÁRIO DE PESQUISA}

A pesquisa utilizou como cenário o programa "Bom Negócio Paraná", que teve sua origem em programa homônimo, desenvolvido pela prefeitura de Curitiba no ano de 2005. A partir de 2011, o governo do estado decidiu adotar a metodologia do programa originado em Curitiba e expandir para todo o estado do Paraná (SEIM, 2013).

O programa tem como objetivo promover o desenvolvimento econômico local dos municípios do Paraná, através da capacitação, consultoria e acompanhamento de empreendedores, fortalecendo as iniciativas que possam resultar na sustentabilidade das empresas e na geração de novos negócios. Está voltado prioritariamente às micro e pequenas empresas dos setores industrial, comercial e de serviços, induzindo a geração de empregos e renda e melhorando a qualidade de vida da população. O programa é viabilizado por meio de parcerias com instituições de ensino, agentes ligados ao desenvolvimento empresarial, órgãos e instituições de caráter público e/ou privado (FOMENTO PARANÁ, 2012).

O curso de capacitação é composto por cinco módulos, com as disciplinas de Gestão de Negócios, Gestão Comercial, Gestão Financeira, Gestão de Pessoas e Gestão Estratégia, com carga horária total de 66 horas. Além disso, os participantes recebem consultoria durante a vigência do programa, que é direcionada às áreas administrativa, econômica, contábil e de direito empresarial. Para isso, os instrutores contam com o apoio de docentes da Universidade Estadual do Oeste do Paraná (Unioeste), em suas respectivas áreas de conhecimento (SEIM, 2013).

\section{ANÁLISE E RESULTADOS}

Inicialmente, foi analisado o perfil dos respondentes, através de informações como o sexo, idade e escolaridade. Dos 101 respondentes, 46,5\% são do sexo masculino e $39,6 \%$ do sexo feminino. No que se refere à idade, entre os 87 questionários respondidos, $25,7 \%$ dos respondentes têm entre 20 e 29 anos, $25,7 \%$ entre 30 e 39 anos, 27,7\% de 40 a 49 anos, 5,9\% entre 50 e 59 anos e $3 \%$ entre 60 e 69 anos. No quesito escolaridade, $100 \%$ dos questionários foram respondidos, sendo que 64,4\% possuem o Ensino Médio, 26,7\% possuem ensino superior e 8,9\% possuem pós-graduação. Ao comparar os dados de perfil dos respondentes da pesquisa com o relatório do Global Entrepreneurship Monitor (GEM) no Brasil, em 2013, o gênero masculino ainda se apresenta com maiores percentuais em relação a empreendimentos estabelecidos; no tocante a faixa etária, há certa convergência com a pesquisa, apenas diferenciando-se em relação a empreendimentos iniciais; por fim, a escolaridade na pesquisa apresentou-se superior à média nacional em relação ao segundo grau completo e ensino superior.

Para analisar o perfil das empresas, foram considerados os quesitos tempo de fundação da empresa, número de funcionários, receita operacional bruta e setor de atuação. No que se refere ao tempo de fundação da empresa, a maior média concentrou-se nas empresas que já atuam de 1 a 5 anos na área, conforme a Tabela 2. 
Tabela 2 - Tempo de fundação da empresa

\begin{tabular}{c|c|c}
\hline Tempo de fundação & Total & $\%$ \\
\hline De 1 mês a 1 ano & 12 & 11,9 \\
De 1 ano a 5 anos & 37 & 36,6 \\
De 5 anos a 10 anos & 17 & 16,8 \\
De 10 anos a 15 anos & 04 & 04,0 \\
Acima de 15 anos & 14 & 13,9 \\
\hline Não responderam & 17 & 16,8 \\
\hline Total & 84 & 100 \\
\hline
\end{tabular}

Fonte: dados da pesquisa (2013).

De acordo com um estudo do Instituto Brasileiro de Geografia e Estatística (IBGE) sobre a longevidade das empresas brasileiras, constatou-se que, de cada cem empresas abertas no Brasil, 48 encerraram suas atividades em três anos. Segundo a pesquisa, divulgada no segundo semestre de 2012, de um total de 464.700 firmas que iniciaram suas atividades no Brasil em 2007, $76,1 \%$ continuavam no mercado em 2008, 61,3\% sobreviveram até 2009 e apenas 51,8\% ainda estavam abertas em 2010, ou seja, quase a metade pereceu no caminho (IBGE, 2012). Fazendo uma comparação com o tempo de atuação das empresas participantes do programa estadual "Bom Negócio Paraná", pode-se observar que elas encontram-se acima da média nacional pelo tempo de permanência no mercado.

A questão referente ao número de funcionários das empresas apresentou $99 \%$ dos questionários respondidos (100 respondentes); destes, 97\% têm até 19 funcionários e apenas $3 \%$ possuem de 20 a 99 funcionários. Considerando a receita operacional bruta no ano de 2012 , $100 \%$ dos respondentes indicaram a alternativa que se refere a um faturamento de até $2,4 \mathrm{mi}-$ Ihões de reais. Dessa forma, pelo número de funcionários e receita operacional, as empresas atendem aos requisitos do programa estadual "Bom Negócio Paraná", que está voltado prioritariamente às micro e pequenas empresas dos setores industrial, comercial e de serviços.

Outra questão refere-se ao setor de operações da empresa, diferenciado entre indústria, comércio e serviço. Foram respondidos $100 \%$ dos questionários; destes, 19,8\% (que totalizam 20 empresas) são indústrias, 31,7\% (que correspondem a 32 empresas) são do comércio e $48,5 \%$ (que somam 49 empresas) são prestadores de serviços.

\subsection{Análise do Instrumento de Medida da Atitude Empreendedora}

Inicialmente, foi efetuada uma análise da confiabilidade do questionário nas respostas das dimensões do Imae, através do Alfa de Cronbach, que resultou em um índice de 0,947. De acordo com Field (2009), os valores entre 0,7 e 0,8 são geralmente aceitáveis, sendo que o índice perfeito é 1,0, possibilitando uma análise estatisticamente descritiva.

Para a análise dos dados, foram utilizados os valores da média, moda, frequência e desvio-padrão de cada questão, divididos nas quatro dimensões propostas pelo instrumento, que são realização, planejamento, poder e inovação. As médias variaram de 7,38 a 9,34, o que indica que os participantes respondentes adotam com frequência as atitudes descritas nas questões. A Tabela 3 descreve as questões com maiores médias de concordância encontradas na pesquisa. 
Tabela 3 - Questões com maiores médias do Imae

\begin{tabular}{|c|c|c|}
\hline Questões & Dimensão & Média \\
\hline 8) "Responsabilizo-me pela conclusão dos trabalhos nos prazos estipulados." & Realização & 9,34 \\
\hline 10) "Confio na minha capacidade de superar desafios." & Poder & 9,17 \\
\hline 26) "Confio na minha competência como fonte do sucesso do meu negócio." & Poder & 9,11 \\
\hline 21) "Busco novas soluções para atender necessidade de clientes." & Inovação & 9,06 \\
\hline 19) "Consulto meus registros de controle antes de tomar decisões." & Planejamento & 8,97 \\
\hline 27) "Emprego esforços extras para a conclusão de tarefas programadas." & Realização & 8,94 \\
\hline 28) "Desenvolvo ideias novas para a solução de problemas." & Inovação & 8,93 \\
\hline $\begin{array}{l}\text { 6) "Adoto procedimentos para assegurar que o trabalho atenda padrões de } \\
\text { qualidade previamente estipulados." }\end{array}$ & Planejamento & 8,66 \\
\hline
\end{tabular}

Fonte: dados da pesquisa (2013).

Com relação ao desvio-padrão, que indica o quão próximos os valores estão da média do conjunto de dados, no geral, verificou-se que eles variam entre 1,098 e 2,557, isto é, esses dados podem estar de 1 a 2 unidades acima ou abaixo da média. A moda, que é o valor mais repetido no conjunto de valores apresentado, manteve-se entre 8 e 10, e a maior frequência entre todas as questões apresentadas obteve uma média de $41,99 \%$.

Ao analisar cada uma das dimensões, as médias variaram entre 8,20 e 8,70, demonstrando-se um alto grau de concordância dos respondentes com as afirmativas apresentadas no questionário. A Figura 1 apresenta um panorama geral das quatro dimensões apuradas.

Figura 1 - Média das dimensões

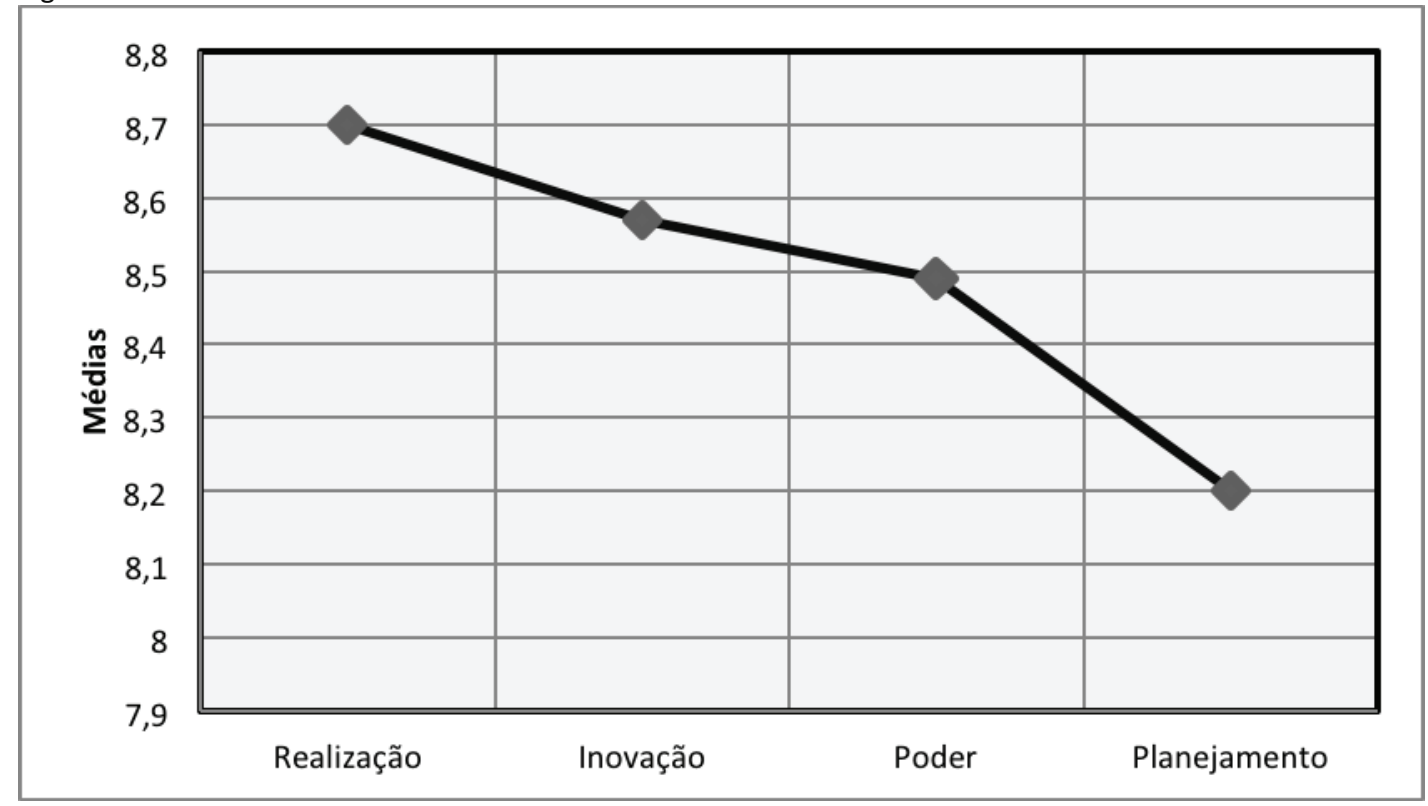

Fonte: dados da pesquisa (2013).

A atitude de realização obteve uma média de concordância de 8,70 , sendo considerada na pesquisa como a dimensão do Imae mais destacável. Esse resultado é compatível com a pesquisa realizada por Pedrosa e Souza (2009) com gerentes de hotéis de Brasília, na qual evidenciaram uma média geral na dimensão realização em 9,5 . Um dos resultados encontrados na pesquisa realizada por Beugelsdijk e Noorderhaven (2004), cujo objetivo era comprovar a relação entre atitude empreendedora e crescimento econômico em uma população composta de 54 regiões 
da Europa, foi que os empreendedores têm uma forte necessidade de alcançar resultados, são mais propensos a comportamentos de risco e têm uma forte crença de que as pessoas podem tomar seu destino em suas próprias mãos. De acordo com o relatório do GEM no Brasil em 2013, cerca de 53,1\% dos entrevistados possuem uma atitude voltada à dimensão de realização, o que evidencia sua particularidade no comportamento dos empreendedores.

A dimensão inovação, com uma média acumulada de 8,57 de concordância em uma escala de 10 pontos, foi a segunda maior média dimensional do Imae na pesquisa. Essa dimensão trata da busca por novas soluções para atender à necessidade de clientes e garantir o bom desenvolvimento de ideias novas para a solução de problemas. No caso específico da pesquisa, o resultado em parte está acompanhando o da dimensão de realização, que é o aproveitamento de oportunidades e a propensão ao risco, características concretizadas através de atividades inovativas.

Marquesini (2007), em sua pesquisa dissertativa utilizando-se do Imae em uma população de 313 gestores de empresas metalúrgicas do estado do Paraná, obteve na dimensão inovação a média geral de 8,2 , convergindo, desse modo, nos resultados encontrados pela pesquisa em tela. Porém, ao observar os dados levantados pelo relatório GEM-Brasil no ano de 2013, percebe-se uma divergência significativa entre as atitudes e a realidade das micro e pequenas empresas brasileiras, sejam iniciantes, sejam estabelecidas no mercado. Cerca de $99,70 \%$ dos participantes da pesquisa relataram possuir tecnologias com mais de cinco anos, concentrandose em mercados com baixas barreiras de entrada e nível tecnológico baixo. Essa interessante constatação deve ter um aprofundamento para sua maior compreensão.

A dimensão de poder atingiu uma média geral de 8,49 em uma escala de concordância de 10 pontos. Por estar relacionada com os aspectos comportamentais de liderança, autoconfiança e persuasão e a capacidade de influenciar as redes de contato, está intimamente ligada às relações grupais que o empreendedor possui. Marquesini (2007) apurou uma média geral na dimensão de poder de 8,47, sendo considerada a maior média entre as quatro dimensões avaliadas pelo Imae. Mintzberg, Ahlstrand e Lampel (2010) destacam a divisão do poder dentro das organizações: no contexto micro, voltado às relações internas, enfatiza a atitude de persuasão; já o poder macro evidencia as relações com o ambiente externo, onde a atitude predominante é a influência.

A dimensão de planejamento obteve a menor média em relação às demais dimensões, com uma média geral de 8,20 , o que não retira sua alta percepção de concordância dos respondentes da pesquisa. Essa dimensão refere-se às habilidades gerenciais que os empreendedores possuem para buscar e processar informações do meio externo e formular estratégias, bem como implementá-las em planos de ações. Marquesini (2007) obteve uma média geral nessa dimensão de 8,3, estando compatível com os resultados encontrados na pesquisa em pauta. Segundo Mintzberg, Ahlstrand e Lampel (2010), o planejamento em organizações empreendedoras muitas vezes se confunde com a articulação visionária do empreendedor, que age centralizando o seu poder, sendo as estratégias implementadas de forma ousada e em condições de incerteza.

\subsection{Análise das dimensões de acordo com o setor das empresas}

Como o objetivo da pesquisa foi analisar a existência de diferenças nas atitudes dos empreendedores em relação aos setores econômicos nos quais estão inseridos os seus empreendimentos, foram realizados alguns testes estatísticos. Inicialmente, realizou-se um teste para verificar a normalidade de distribuição dos dados por dimensão. Tanto pelo teste Kolmogorov-Smirnov como pelo Shapiro-Wilk, constatou-se que as dimensões realização, planejamento, poder e inovação apresentam nível de significância $\rho<0,05$, demonstrando que existe uma significante anormalidade na distribuição, sendo que, das 36 questões variáveis dependentes analisadas, todas apresentaram $\rho<0,001$. 
Na sequência, utilizou-se o teste não paramétrico de Kruskal-Wallis para verificar possíveis diferenças nos postos de escores entre os setores indústria, comércio e serviços. Para isso, criaram-se as hipóteses a serem comprovadas, se $H_{0}$ for $\rho \leq \alpha(0,05)$, com grau de liberdade 2 :

$H_{0}: A E$ ( $y$ indústria $)=A E$ ( $y$ comércio $)=A E$ ( $y$ serviço $) v s$.

$H_{1}: A E$ (y indústria) $\neq A E$ (y comércio) $\neq A E$ (y serviço)

A seguir, apresentam-se os principais resultados e conclusões referentes à aplicação do referido teste estatístico.

Quadro 3 - Teste não paramétrico Kruskal-Wallis

\begin{tabular}{|c|c|c|c|c|c|c|c|c|c|}
\hline Questões & Q2 & Q4 & Q8 & Q13 & Q17 & Q18 & Q20 & Q27 & Q30 \\
\hline Chi-square & 2,907 & 0,231 & 4,911 & 4,763 & 8,037 & 0,938 & 4,845 & 8,144 & 3,234 \\
\hline Asymp. Sig. & 0,234 & 0,891 & 0,086 & 0,092 & 0,018 & 0,626 & 0,089 & 0,017 & 0,199 \\
\hline Questões & $\mathbf{Q 3}$ & $\mathbf{Q 5}$ & $\mathbf{Q 6}$ & $\mathbf{Q 9}$ & $\mathbf{Q 1 2}$ & $\mathbf{Q 1 5}$ & $\mathbf{Q 1 6}$ & $\mathbf{Q 1 9}$ & Q22 \\
\hline Chi-square & 3,375 & 1,342 & 1,76 & 0,207 & 6,168 & 0,800 & 2,777 & 0,282 & 2,037 \\
\hline Asymp. Sig. & 0,185 & 0,511 & 0,415 & 0,902 & 0,046 & 0,670 & 0,249 & 0,868 & 0,361 \\
\hline Questões & $\mathbf{Q 2 9}$ & $\mathbf{Q 3 2}$ & $\mathbf{Q 3 3}$ & $\mathbf{Q 3 4}$ & $\mathbf{Q 7}$ & $\mathbf{Q 1 0}$ & $\mathbf{Q 1 4}$ & $\mathbf{Q 2 4}$ & $\mathbf{Q 2 5}$ \\
\hline Chi-square & 4,282 & 2,892 & 0,094 & 0,513 & 1,811 & 2,141 & 0,275 & 7,132 & 3,259 \\
\hline Asymp. Sig. & 0,118 & 0,235 & 0,954 & 0,774 & 0,404 & 0,343 & 0,872 & 0,028 & 0,196 \\
\hline Questões & $\mathbf{Q 2 6}$ & $\mathbf{Q 3 5}$ & $\mathbf{Q 3 6}$ & $\mathbf{Q 1}$ & $\mathbf{Q 1 1}$ & $\mathbf{Q 2 1}$ & $\mathbf{Q 2 3}$ & $\mathbf{Q 2 8}$ & $\mathbf{Q 3 1}$ \\
\hline Chi-square & 3,350 & 3,972 & 0,215 & 4,686 & 3,683 & 2,475 & 5,858 & 3,427 & 2,267 \\
\hline Asymp. Sig. & 0,187 & 0,137 & 0,898 & 0,096 & 0,159 & 0,290 & 0,053 & 0,180 & 0,322 \\
\hline
\end{tabular}

Fonte: adaptado de Output do Software SPSS 18 (2013).

Conforme o Quadro 3, é possível observar que as questões 17, 27, 12 e 24 apresentaram diferenciações. Na dimensão realização, composta por nove questões, apenas houve diferenciação nas questões 17 , que trata dos sacrifícios pessoais para concluir tarefas, e 27 , que trata do emprego de esforços extras para a conclusão de tarefas programadas. Já na dimensão planejamento, com 13 questões, apenas a questão 12, que trata das projeções claras para o futuro do negócio, teve diferenciação significativa. De acordo com a dimensão poder, abrangendo oito questões, a questão 24 , que trata sobre a responsabilidade pela resolução de problemas que possam prejudicar o desempenho do negócio, apresentou diferenças entre os grupos pesquisados. Quanto à dimensão inovação, que apresenta seis questões, não houve nenhuma diferença significativa, apresentando homogeneidade em todas as questões.

Os resultados apresentados permitem concluir que as diferenças entre os grupos não são significativas em relação às 36 questões de caracterização da atitude empreendedora, pois apenas $11,11 \%$ delas acarretaram em diferenças, podendo-se concluir que há mais semelhanças do que diferenças entre esses grupos abordados na pesquisa.

\subsection{Constatação de diferenças entre os grupos}

Para constatar as diferenças entre os grupos abordados, foi efetuado o teste de Fisher (Lest Significant Difference - LSD), com a rejeição do $\mathrm{H}_{0}$ se $\rho \leq \alpha(0,05)$, com as seguintes hipóteses:

$$
\begin{aligned}
& \mathrm{H}^{1}: \mathrm{AE} \text { (y indústria) }=\mathrm{AE} \text { (y comércio) vs. } \mathrm{H}_{1}{ }_{1}: \mathrm{AE} \text { (y indústria) } \neq \mathrm{AE} \text { (y comércio) } \\
& \mathrm{H}_{0}^{2} \text { : } \mathrm{AE} \text { (y indústria) }=\mathrm{AE} \text { (y serviço) } \quad v s . \mathrm{H}^{2} \text { : } \mathrm{AE} \text { (y indústria) } \neq \mathrm{AE} \text { (y serviço) } \\
& \left.\mathrm{H}^{3} \text { : } \mathrm{AE} \text { (y comércio) }=\mathrm{AE} \text { (y serviço) } \quad \text { s. } \mathrm{H}^{3}{ }_{1} \text { : } \mathrm{AE} \text { (y comércio }\right) \neq A E \text { (y serviço) }
\end{aligned}
$$


Nas questões 17 e 27, referentes à dimensão realização, $\rho=0,04$ e $\rho=0,05$, respectivamente. Há uma diferença significativa no setor comércio, havendo uma intensidade menor no sacrifício pessoal para concluir tarefas e emprego de esforços extras para concluir tarefas programadas. A maior diferença está concentrada entre o setor indústria e comércio e, na questão 27 , também há uma diferença $\rho=0,021$ entre o setor da indústria e serviços.

Na questão 12 , referente à dimensão planejamento, o setor comércio apresentou $\rho=$ 0,017 , havendo diferença com o setor da indústria. Também nesta mesma questão o setor de serviços $\rho=0,035$ possui diferença em relação ao setor da indústria. Na questão 24 , referente à dimensão poder, ocorreram diferenças entre o setor de serviços $\rho=0,009$ e o setor da indústria.

Ao comparar as respostas das questões entre os setores, a indústria e o comércio apresentaram as maiores diferenças entre si, sendo quase mínimas em relação ao valor total de questões. Conclui-se, então, que existem neste cenário de pesquisa tênues diferenças na atitude empreendedora entre os setores indústria, comércio e serviços.

\section{CONSIDERAÇÕES FINAIS}

Com o auxílio do instrumento Imae, foi possível verificar as atitudes empreendedoras mais predominantes dos participantes do programa estadual "Bom Negócio Paraná" da cidade de Francisco Beltrão. Ao analisar as respostas dos participantes de acordo com as quatro dimensões, verificou-se que a dimensão que recebeu maior indicador geral foi a da realização, com média de 8,70. Em segundo lugar, destacou-se a dimensão inovação, com média 8,57, seguida pela dimensão poder, com média 8,49, e, por fim, planejamento, com média 8,20. Esses resultados multidimensionais de concordância podem ser explicados por Ajzen (2001), que cita a teoria psicológica do modelo de atitudes duplas, na qual as pessoas podem simultaneamente realizar duas atitudes diferentes em direção a um determinado objeto no mesmo contexto, uma com características implícitas (habituais) e outra explícitas.

Na comparação realizada entre os setores indústria, comércio e serviços, observou-se que, em termos gerais, houve diferenças tênues entre os três setores avaliados, já que, em relação às 36 questões de caracterização da atitude empreendedora analisadas, apenas quatro variáveis, representadas por três dimensões (planejamento, poder e realização), acarretaram em diferenças, sendo que apenas a dimensão inovação não obteve diferenciações de concordância entre os setores. Desse modo, a pesquisa propôs uma perspectiva diferente de análise em relação ao trabalho de Bosma e Schutjens (2007), que exploraram as atitudes empreendedoras com diferenciações espaciais na Europa, analisando o atributo de setores econômicos como vetores de distinção.

Sugere-se, para futuras pesquisas, a continuidade da aplicação do presente questionário em outras turmas do programa estadual "Bom Negócio Paraná", em outros núcleos distribuídos nas regiões geográficas do estado do Paraná, aperfeiçoando a análise com a variável regional, podendo fazer-se um comparativo para confirmar os resultados da pesquisa em tela. Para um aprofundamento maior, haveria a necessidade de utilizar o método misto explanatório, dividido em duas fases, sendo a primeira quantitativa, com a utilização de análise fatorial como forma de reduzir as variáveis, e uma fase qualitativa, com entrevistas com uma amostragem menor, com a finalidade de compreender a percepção dos empreendedores com relação às suas atitudes de empreendedorismo. 


\section{REFERÊNCIAS}

AJZEN, I. Nature and operation of atitudes. Annu. Rev. Psychol, n. 52, p. 27-58, 2001. Disponível em: <http://www.annualreviews.org/doi/pdf/10.1146/annurev.psych.52.1.27>. Acesso em: 20 fev. 2016.

BERNARDI, L. A. Manual do empreendedorismo e gestão: fundamentos, estratégias e dinâmicas. São Paulo: Atlas, 2003.

BESSANT, J.; TIDD, J. Inovação e empreendedorismo. Porto Alegre: Bookman, 2009.

BITTAR, F. S. O.; BASTOS, L. T.; MOREIRA, V. L. Reflexões sobre o empreendedorismo: uma análise crítica na perspectiva da economia das organizações. ReA - Revista de Administração da UFSM, v. 7, n. 1, mar. 2014. Disponível em: <http://cascavel.ufsm.br/revistas/ojs-2.2.2/index.php/ reaufsm/article/view/569/429>. Acesso em: 20 fev. 2016.

BEUGELSDIJK, S.; NOORDERHAVEN, N. Entrepreneurial attitude and economic growth: a cross section of 54 regions. The anais of Regional Science. Springer-Verlog, 2004. Disponível em: <http://wuw-ruw. wu-wien.ac.at/ersa/ersaconfs/ersa02/cd-rom/papers/142.pdf>. Acesso em: 13 out. 2013.

BOSMA, N.; SCHUTJENS, V. Understanding regional variation in entrepreneurial activity and entrepreneurial attitude in Europe. Ann. Reg. Sci., v. 47, n. 3, p. 711-742, 2011. Disponível em: <https://www.researchgate. net/publication/225679216_Understanding_regional_variation_in_entrepreneurial_activity_and_ entrepreneurial_attitude_in_Europe_Ann_Reg_Sci>.Acesso em 20 out. 2013.

CARVALHO, C. A.; VIEIRA, M. M. F. O poder nas organizações. São Paulo: Thomson Learning, 2007.

DANCEY, C. P.; REIDY, J. Estatística sem matemática para psicologia. Porto Alegre: Artmed, 2006.

DORNELAS, J. C. A. Empreendedorismo: transformando ideias em negócios. 11. ed. Rio de Janeiro: Elsevier, 2001.

DRUCKER, P. F. Inovação e espírito empreendedor: práticas e princípios. São Paulo: Pioneira Thomson, 2003.

FARIA, J. H. O autoritarismo nas organizações. Curitiba: Criar: 1985.

FIELD, A. Descobrindo a estatística usando o SPSS. 2. ed. Porto Alegre: Artmed, 2009.

FOMENTO PARANÁ. Programa Bom Negócio Paraná. Disponível em: <http://www.fomento. pr.gov.br/arquivos/File/Banco_do_Empreendedor/Docs/Panorama_Programa_Bom_Negocio_ Parana.pdf>. Acesso em: 05 out. 2013.

GLOBAL ENTREPRENEURSHIP MONITOR (GEM). Empreendedorismo no Brasil: relatório executivo, 2013. Disponível em: <http://www.sebrae.com.br/Sebrae/Portal\%20Sebrae/Anexos/ Relatorio\%20Executivo\%20GEM\%202013.pdf>. Acesso em 18 out. 2013.

GREATTI, L.; SENHORINI, V. M. Empreendedorismo: uma visão comportamentalista. In: Encontro de estudos em empreendedorismo e gestão de pequenas empresas, 1., 2000, Maringá, PR. Anais... Maringá, PR, out. 2000. p. 22-34, Disponível em: <http://www.anegepe.org.br/ edicoesanteriores/maringa/EMP2000-01.pdf>. Acesso em: 05 out. 2013.

HAIR JR., J. et al. Métodos de pesquisa em administração. São Paulo: Bookman, 2005. 
HASHIMOTO, M. Espírito empreendedor nas organizações. 2. ed. São Paulo: Saraiva, 2010.

HISRICH, R. D.; PETERS, M. P.; DEAN, S. A. Empreendedorismo. 7. ed. Porto Alegre: Bookman, 2009.

Instituto Brasileiro de Geografia e Estatística (IBGE). Disponível em: <http://www.ibge.gov.br/>. Acesso em: 2 out. 2013.

LENGLER, L. Uma análise do comportamento empreendedor e do processo decisional de presidentes de associações apícolas no rio grande do sul. ReA - Revista de Administração da UFSM, v. 1, n. 1, jan./abr. 2008. Disponível em: <http://cascavel.ufsm.br/revistas/ojs-2.2.2/index. php/reaufsm/article/view/611/460>. Acesso em: 28 fev. 2016.

LOPEZ JR., G. S. Atitude empreendedora em proprietários-gerentes de pequenas empresas de varejo: criação de um instrumento de medida. 91 f. 2005. Dissertação (Mestrado em Administração) - Universidade de Brasília, Brasília, 2005.

MARQUESINI, J. B. Atitude empreendedora de dirigentes de empresas metalúrgicas do estado do Paraná. 80 f. 2007. Dissertação (Mestrado em Administração) - Centro Universitário Positivo, Curitiba, 2007.

MAROCO, J. Análise estatística com utilização do SPSS. 3. ed. Lisboa: Edições Sílabo, 2007.

MCCLELLAND, D. C. A sociedade competitiva: realização e progresso social. Rio de Janeiro: Expressão e Cultura, 1972.

MELLO, C. M.; MACHADO, H. V.; JESUS, M. J. F. Considerações sobre a inovação em PMES: o papel das redes e do empreendedor. Revista de Administração da UFSM, v. 3, n. 1, jan./abr. 2010. Disponível em: <http://cascavel.ufsm.br/revistas/ojs-2.2.2/index.php/reaufsm/article/ view/2236/1365>. Acesso em: 25 fev. 2016.

MINTZBERG, H.; AHLSTRAND, B.; LAMPEL, J. Safári de estratégia: um roteiro pela selva do planejamento. 2. ed. Porto Alegre: Bookman, 2010.

ROBBINS, S. Administração. São Paulo: Saraiva, 2000.

PEDROSA, M. A.; SOUZA, E. C. L. Atitude empreendedora no setor hoteleiro brasileiro: um estudo em pequenos e grandes hotéis no distrito federal. Revista Turismo Visão e Ação - Eletrônica, v. 11, n. 3. p. 358-374, set./dez. 2009. Disponível em: <http://siaiap32.univali.br/seer/index.php/ rtva/article/view/503>. Acesso em: 23 out. 2013

SCHUMPETER, J. A. A teoria do desenvolvimento econômico. São Paulo: Abril Cultural, 1982.

. Teoria do desenvolvimento econômico: uma investigação sobre lucros, capital, crédito, juro e o ciclo econômico. São Paulo: Nova Cultural, 1997.

Serviço Brasileiro de Apoio ÀS Micro e Pequenas Empresas (SEBRAE). Disponível em: <http:// www.sebrae.com.br>. Acesso em: 11 ago. 2013.

Secretária da Indústria, Comércio e assuntos do Mercosul (SEIM). Disponível em: <http://www. seim.pr.gov.br/modules/conteudo/conteudo.php?conteudo=220>. Acesso em: 05 ago. 2013. 